\title{
A PSICOLOGIA POSITIVA COMO FOMENTADORA DO BEM-ESTAR E DA FELICIDADE
}

\author{
Ludgleydson Fernandes de Araújo ${ }^{1}$ \\ Universidade Federal do Piauí, Parnaíba-PI, Brasil
}

Nos últimos anos têm aumentado os estudos sobre os aspectos positivos das emoções e do comportamento humano. Historicamente, a ciência psicológica tem dado maior ênfase a pesquisas em psicopatologia e aos aspectos menos saudáveis dos indivíduos. A Psicologia clássica priorizou o patológico e, seguindo este caminho, esqueceu-se de aspectos emocionais construtivistas como o bem-estar psicológico, a satisfação com a vida, a paz ou prazer, ignorando os benefícios que eles proporcionam aos indivíduos (Seligman \& Csikszentmihalyi, 2001).

O psicólogo Martin Seligman, um dos pioneiros da Psicologia Positiva (PsP), escreveu um livro intitulado Florescer - uma nova e visionária interpretação da felicidade e do bem-estar (2011), que tenta mostrar esse paradigma da Psicologia fora do âmbito científico. $O$ autor dos livros "Felicidade Autêntica" (2002) e "Otimismo aprendido" (2004) apresenta em sua nova publicação aspectos teóricos e práticos para desenvolver o otimismo, a motivação e as características da resiliência que são necessárias para que as pessoas desenvolvam o bem-estar psicológico.

Neste livro o autor apresenta a teoria da felicidade autêntica a partir de cinco elementos básicos: 1) a emoção positiva, que é a pedra angular da teoria de bem-estar; 2) a entrega (viver o momento presente); 3) o sentido (as idiossincrasias da vida); 4) sucessos (indivíduos que perseguem o sucesso); e 5) relações (os outros indivíduos). O livro é dividido em duas partes, das quais a primeira se intitula "Nova psicologia positiva", e a segunda tem como título "Os caminhos para o crescimento pessoal". $\mathrm{Na}$ primeira parte Seligman destaca o paradigma da PsP, analizando como é este novo paradigma do conhecimento psicológico. O autor faz distinção entre a Teoria da Felicidade Autêntica e a Teoria do Bem-Estar. A primeira analisa como seria medir o construto psicológico por meio da satisfação com a vida, e a segunda trata de como aumentar a emoção positiva, ou seja, as relações positivas e a autorrealização.

Assim, o autor propõe exercícios PsP para aumentar o bem-estar e diminuir fatores inerentes à depressão. Um primeiro exercício seria "Visita de agradecimento", que consiste em alguém escrever uma carta de agradecimento a uma pessoa importante em sua vida. Outro exercício seria o das "Três bênçãos", em que se escrevem três coisas que correram bem durante um dia, considerandose o porquê de isso ter acontecido dessa forma. Além disso, propõe uma terceira tarefa sobre as fortalezas pessoais: a de encontrar novas formas de uso e frequência. Posteriormente é apresentada a psicoterapia positiva, em que inicialmente são identificados os níveis de bem-estar de uma pessoa por meio de respostas a um questionário contido no site www.authentichhappiness.org; em seguida são analisados sintomas depressivos e realizadas sessões de psicoterapia positiva para adaptação positiva.

Martin Seligman escreveu um capítulo intitulado "O pequeno segredo sujo dos medicamentos e terapia". Nele o autor faz a afirmação controversa de que "não há nenhuma droga em desenvolvimento que visa a cura" e que a Psiquiatria e a Psicologia Clínica teriam desistido da ideia de cura. Desta forma, os resultados das psicoterapias tradicionais são lentos e, como afirma Seligman, na maioria dos casos os efeitos não são os desejados. O autor reflete sobre a chamada "Barreira $65 \%$ ", em que i índice de placebo é muito elevado na maioria dos estudos, chegando a atingir

1 Endereço para correspondência: Universidade Federal do Piauí - Departamento de Psicologia - Campus de Parnaíba, Av. São Sebastião, 2819, CEP 64.202-020, Parnaíba-PI, Brasil.E-mail: ludgleydson@yahoo.com.br. 
45 a $55 \%$. Na Educação, este livro destaca o capítulo intitulado "Educação Positiva: o ensino do bem-estar da juventude", em que o autor afirma que o tema Emoções positivas deve ser abordado com os alunos na escola, a fim de evitar futuros problemas psicológicos e fortalecer a vidas das pessoas. O programa Resiliência é destaque na Universidade da Pensilvânia (EUA), pois reduz e previne sintomas depressivos, desesperança e ansiedade e melhora os comportamentos relacionados à saúde. Para concluir esta primeira parte do libro, Seligman sugere que o PIB (produto interno bruto) não seja quantificado pelos bens e serviços que as pessoas possuem, mas pela produção de bem-estar.

$\mathrm{Na}$ segunda parte do livro, inicialmente é apresentada a "Determinação, caráter e realizações", em que o autor ainda afirma não saber nada sobre a forma de aumentar o ritmo de aprendizagem, mas o que se sabe de verdade é que o tempo gasto na tarefa funciona, basicamente de duas maneiras 1) com a capacidade e 2) com o conhecimento existente. Assim, a ciência da PsP poderá ser importante para a geração de comportamentos que aumentam a determinação e o autocontrole. $\mathrm{O}$ autor ensina uma experiência, talvez uma das mais gratificantes, para ilustrar o uso prático do conhecimento da PsP na vida das pessoas. É um procedimento chamado "Um exército em formação: aptidão militar global", em que se tenta construir a resiliência como um modelo para prevenir, entre os militares dos EUA, o estresse pós-traumático, a depressão e o suicídio. Com a ajuda do Pentágono, é oferecido aos militares um curso de formação em que os participantes respondem inicialmente a um instrumento chamado Ferramenta de Avaliação Global (FAG), com quatro áreas: competência emocional, competência social, aptidão familiar e aptidão espiritual. As conclusões iniciais mostram que os sintomas de estresse postraumático diminuem com o aumento da competência emocional.

Não há como negar que a resiliência tem ajudado na superação de adversidades nas forças armadas. No capítulo seguinte, o autor relata como "Converter o trauma crescendo", com o objetivo de abordar os exercícios usando seus pontos fortes ao invés de apenas explorar os pontos fracos, como na psicologia tradicional. No penúltimo capítulo de "Saúde física positivo: a biologia do otimismo", o autor afirma que a PsP considera a saúde mental não apenas como a ausência de doença mental. Observa que a Medicina e a Psicologia necessitam mudar o paradigma e criar um novo que leve em conta os efeitos do fortalecimento das situações positivas. O autor destaca um ponto interessante: as pessoas pessimistas se deprimem mais do que as otimistas, do mesmo modo que têm baixo desempenho no trabalho, em sala de aula e nos esportes e que nas relações são mais instáveis. Um fato interessante que se destaca neste capítulo é que o bem-estar funciona como um fator protetor contra doenças futuras como insuficiência renal, acidente vascular cerebral e HIV. No final deste capítulo Seligman (2011) faz uma declaração pouco parcimoniosa: "Concluo que o risco de câncer pode ser menor para muito otimista. Conclui-se que o risco de mortalidade é menor para pessoas saudáveis com alto bem-estar psicológico" (p.239).

Finalmente, o autor escreve um capítulo em sintonia com o contexto da crise econômica internacional, intitulado "Política e economia do bem-estar", que começa com a pergunta "O que é riqueza?". O capítulo constitui-se de uma interessante reflexão sobre o abismo do PIB e e sua relação com o bem-estar. É relatado que o PIB não traduz o bem-estar tenham as pessoas, mas apenas a quantidade de riqueza material (bens e serviços) produzida pela humanidade. Propõe-se uma "Economia positiva", em que o bem é desenvolvido nos campos da emoção positiva, entrega, realizações positivas, relacionamentos positivos e significado. Seligman termina o livro afirmando que "tudo o que podemos dizer sim é para mais bem-estar."

No geral, observa-se que o livro em questão fornece reflexões importantes e relevantes para a compreensão do bem-estar e da felicidade, com uma linguagem acessível, com o objetivo de massificar a PsP, ou seja, trazer o conhecimento científico para a população em geral; no entanto são necessárias mais investigações longitudinais para demonstrar que fatores influenciam a formação da resilência e do bem-estar. O livro contribui sobremanera para propagar o bem-estar e a felicidade das pessoas.

\section{REFERÊNCIAS}

Seligman, M. E. P. (2011). Florescer - uma nova e visionária interpretação da felicidade e do bem-estar. Rio de Janeiro: Objetiva.

Seligman, M. E. P. (2004). Aprenda optimismo. Barcelona: DeBolsillo.

Seligman, M. E. P. (2003). Felicidade Autêntica. Rio de Janeiro: Ponto de Leitura 
Seligman, M. E. P. \& Csikszentmihalyi, M. (2001).

Positive psychology: an introduction. American Psychologist, 55(1), 5-14.

Ludgleydson Fernandes de Araújo: psicólogo, mestre em Psicologia pela Universidade Federal da Paraíba, mestre e doutorando em Psicologia da Saúde pela Universidad de Granada, Espanha; professor assistente do Departamento de Psicologia da Universidade Federal do Piauí - Campus de Parnaíba-PI. 